\title{
LEVANTAMENTO, CADASTRAMENTO E ESTIMATIVA POPULACIONAL DAS HABITAÇÕES DE MORCEGOS HEMATÓFAGOS, ANTES E APÓS ATIVIDADES DE CONTROLE, NO MUNICÍPIO DE ARAGUARI, MG
}

\section{P.R. de Oliveira ${ }^{1}$, D.A.R. Silva ${ }^{2}$, J.H. Rocha ${ }^{3}$, S.M.A. de Melo ${ }^{4}$, N.G. Bombonato ${ }^{1 *}{ }^{,}$, F.O. Carneiro e Silva ${ }^{1}$}

${ }^{1}$ Universidade Federal de Uberlândia, Faculdade de Medicina Veterinária, Campus Umuarama, Av. Pará, 1720, Bloco 2T, CEP 38400-902, Uberlândia, MG, Brasil. E-mail: profpaul@bol.com.br

\section{RESUMO}

\begin{abstract}
Os morcegos hematófagos são responsáveis pela transmissão da raiva dos herbívoros, zoonose de maior importância em saúde pública. Neste estudo, foram pesquisadas habitações desses morcegos no Município de Araguari, MG, no período entre 1996 e 2003, com o objetivo de localizar e cadastrar abrigos naturais e artificiais que acolhiam hematófagos, visando controle populacional, estimativa da mediana nas colônias e identificação das espécies encontradas. Foram cadastrados 54 abrigos, agrupados em 12 tipos diferentes, do Desmodus rotundus, espécie de hematófago mais frequente no Brasil. Dentre o total de abrigos $81,5 \%$ eram artificiais, conforme ordem decrescente de suas frequências: casas, bueiros, pontilhões, pontes, etc., enquanto que entre os $18,5 \%$ dos naturais, as cavernas e ocos de árvores foram os mais frequentes. Dos abrigos habitados pelo $D$. rotundus, 82,4\% possuíam população estimada entre 1 a 50 hematófagos e 17,6\% entre 51 a 300 indivíduos, com população mediana de 30,2 por abrigo. Após o tratamento com warfarina, 72,5\% dos abrigos foram desabitados. Para o controle efetivo da raiva dos herbívoros é necessário que se mantenha uma rotina de cadastro dos abrigos, com monitoramento de pelo menos uma vez por ano.
\end{abstract}

PALAVRAS-CHAVE: Quirópteros, Desmodus rotundus, raiva, controle.

\section{ABSTRACT}

SURVEY,REGISTRATIONANDPOPULATIONESTIMATEOFHEMATOPHAGOUS(VAMPIRE) BATHABITATS, BEFOREAND AFTERCONTROL ACTIVITIES, INTHECOUNTYOF ARAGUARI, MG, BRAZIL. Vampire bats are responsible for the transmission of herbivorous rabies, a zoonosis of the greatest importance to public health. In the present study the habitats of these bats were investigated in the County of Araguari, MG, Brazil, in the period between 1996 and 2003. The objective of the investigation was to locate and register the natural and artificial shelters with hematophagous bats, estimating the median population of the colonies and the identification of the species found therein, having in mind their population control. A total of 54 shelters of Desmodus rotundus, the most frequently found hematophagous bat in Brazil were registered and grouped in 12 different kinds. In terms of their location, $81.5 \%$ of these shelters were in man-made objects, listed in regard to the decreasing order of their frequency: houses, drains, small bridges, bridges, etc., while $18.5 \%$ were in natural sites, of which caves and hollows in trees were the most frequent. Of the shelters inhabited by D. rotundus, $82.4 \%$ had an estimated population between 1 to 50 individuals, while $17.6 \%$ had between 51 and 300 individuals, with a median population of 30.2 per shelter. After treatment with Warfarin, $72.5 \%$ of the shelters were unoccupied. For effective control of rabies in herbivores it is necessary to maintain a routine registry of shelters with monitoring at least once a year.

KEY WORDS: Vampire bats, Desmodus rotundus, rabies, control.

\footnotetext{
${ }^{2}$ Médica Veterinária, Araguari, MG, Brasil.

${ }^{3}$ Médico Veterinário-IMA, Araguari, MG, Brasil.

${ }^{4}$ Coordenação da Política Nacional de Sangue e Hemoderivados/DAE/SAS/MS, Brasilia, DF, Brasil.

*Mestranda do Programa de Pós-Graduação, Universidade Federal de Uberlândia, MG.
} 


\section{INTRODUÇÃO}

Os morcegos são os únicos mamíferos com capacidade devoo, devidoà transformação de seus braços em asas. Pertencem à ordem Chiroptera, palavra que significa mão (chiro) transformada em asa (ptera). É possível identificar, em sua asa aberta, o braço, o antebraço e a mão. Na mão podem-se observar todos os dedos: o polegar (único dedo com unha nos morcegos das Américas), os metacarpos e as falanges dos dedos. A ordem Chiroptera compreende cerca de 1.000 espécies em todo o mundo (HUSSON, 1962; BRASIL 2005).

Estão distribuídos em duas subordens, a Megachiroptera ea Microchiroptera, além de 18 famílias e de 168 gêneros. A subordem Megachiroptera contém apenas a família Pteropodidae, que está restrita ao Velho Mundo (África, Ásia e Oceania). A subordem Microchiroptera é de ampla distribuição geográfica e inclui 17 famílias, dentre as quais nove ocorrem no Novo Mundo (América doNorte, Central e do Sul) (Cunha-Vieira, 1942). Na família Phyllostomidae (subfamília Desmodontinae) da subordem Microchiroptera estão incluídas as três espécies de morcegos que possuem hábito alimentar hematófago. Duas atacam aves, Diphylla ecaudata e Diaemus youngi, uma ataca avese mamíferos, Desmodus rotundus (KoOPMAN, 1988).

No Brasil existem cerca de 200 espécies de morcegos capazes de utilizar os mais diversificados nichos ecológicos, com importância fundamental para oequilíbrio do ecossistema. Todas as três espécies de morcegos hematófagos são encontradas no Brasil (KOOPMAN, 1988; BiAnCONI et al., 2004). A maisestudada é a $D$. rotundus, por ser a mais abundante e pela sua importância econômica e social. Tem ampla distribuição no Novo Mundo, ocorrendo desde o norte do México, América Central e até o norte da Argentina (AlENCAR, 1977; BRASIL, 2005).

Os fatores mais importantes que determinam a abundância de espécies de morcegos são a distribuição de alimentos e de abrigos. A maior presença de hematófagos nesses abrigos deve-se às condições ambientais favoráveis como temperatura ambiente, umidade relativa do ar e pouca luminosidade (BREDT, 1996). Eles devem oferecer condições que permitamo acasalamento, parto, criação de filhotes, interações sociais, digestão do alimento consumido durante a noitee, ainda, proteção contra intempéries ambientais (chuvas, vento e insolação) e contra possíveis predadores (YALDEN; MORRIS, 1975).

Os morcegos hematófagos habitam grandes variedades de abrigos tais como: grutas de pedra, túneis, poços d'água, bueiros e mais raramente ocos deárvores e telhados de residências (HILL; SMITH, 1984). Somente saem do abrigo após total escuridão e em ausência da luz da lua, têm hábitos exclusivamente noturnos.Seencontradosduranteodia, fora dohabitat, fatalmenteestão enfermos eprovavelmente com raiva (FloRES-CRESPO et al., 1972). A colônia dos morcegos hematófagos fica distintamente separada das demais espécies, que podem ou não habitar o mesmo refúgio (HILL; SMITH, 1984).

Causa preocupação o registro da presença do $D$. rotundus em áreas urbanas. Ele já foi encontrado na região metropolitana de São Paulo, Belo Horizonte e Rio de Janeiro, constatando ataques a pessoas nas duas últimas cidades. Registrou-se sua presença na periferia decidadessatélites do Distrito Federal(UIEDA, 1995).

Nos Estados Unidos os morcegos são os principais transmissores da raiva para seres humanos(HuNT; BHATNAGAR, 1997). No Brasil, até2003, o envolvimento de morcegos na transmissão da raiva a humanos era descrito com baixa frequência. Em 2005, dos 45 casos registrados de raiva humana, 42 foram transmitidos por morcegos hematófagos (BRASIL, 2005).

Os mamíferos apresentam dois ciclos principais de transmissão da raiva: urbano e silvestre. As principais fontes de infecção no ciclo urbano são o cão e o gato, sendo o morcego hematófago o principal responsável pela manutenção da cadeia silvestre (GONÇALVES, 1996; BRASIL, 2005).

Economicamente, omorcego hematófago da espécie $D$. rotundus pode trazer grandes prejuízos para a pecuária, uma vez que é o principal transmissor da raiva dos herbívoros, e por ser abundante em regiões de exploração dessa atividade (Acha; Málaga-Alba, 1988).

Além dos prejuízos diretos causados pela raiva, os morcegos hematófagos contribuem para a diminuição da qualidade do couro, enfraquecimento e perda depeso dos animais, infecções bacterianas (Salmonella e Shigella, Brucella), viróticas (Encefalite Venezuelana Equina e Febre Amarela) e miíases nos ferimentos, em consequência das mordeduras (BREDT, 1996).

Portanto, o desenvolvimento de técnicas de controle das populações desses hematófagos torna-se uma estratégia importante como medida na diminuição da incidência da raiva, como também, de outras zoonoses (PICCININI, 1982). Esse controle é feito por meio de várias medidas, como levantamento de abrigos naturais e artificiais, capturas nesses abrigos, inviabilização de abrigos artificiais, estímulo e orientação para a localização e notificação rotineira da existência de novos abrigos (Котагт et al., 1998).

O Ministério da Saúde, desde 1966, por meio da Divisão de Defesa Sanitária Animal, instituiu o Plano de Combateà Raiva dos Herbívoros, que atualmente denomina-sePrograma NacionaldeControleda Raiva dos Herbívoros (PNCRH), executado pelo Departamento de Saúde Animal (SDA), do Ministério da 
Agricultura, Pecuária e Abastecimento (MAPA) (BRASIL, 2005).

As pesquisas com quirópteros precisam ser intensificadas, pois somente desta forma mais conhecimentos poderão ser adquiridos e assim empregados no controle da raiva dos herbívoros e da raiva humana. Há ainda que se salientar a transmissão de outras zoonoses pelos quirópteros, tais como: histoplasmose, arboviroses, tripanossomose, leptospirose, salmonelose, criptococose e riquetsiose (BREDT, 1996;BREDT, et al., 1998).

O Município de Araguari, MG, tem sido alvo da raiva por apresentar condições propícias para a permanência e sobrevivência de morcegos hematófagos, principalmente devido à vegetação típica do cerrado que abriga também mamíferos silvestres suscetíveisà raiva. Neste município, a relação dos resultados de análises laboratoriais, feitas nos anos de janeiro de 2000 até dezembro de 2002, nos laboratórios do Instituto Mineiro de Agropecuária (IMA) em Belo Horizonte, mostrou 26 resultados positivos para raiva provocada por morcego da espécie D. rotundus (Rocha et al., 2003).

O presente estudo se justificou pela necessidade de localizar e cadastrar abrigos naturais e artificiais que acolhiam morcegos hematófagos, no Município de Araguari, MG, visando o controle populacional, bem como estimar a população mediana das colônias nesses abrigos e identificar as espécies hematófagas encontradas.

\section{MATERIALEMÉTODOS}

\section{Área de estudo}

Foram pesquisados abrigos em 51 propriedades rurais do Município de Araguari, MG, localizado no Triângulo Mineiro, no período entre 1996 e 2003.

A área do município é de $2.729 \mathrm{~km}^{2}$, sendo 54 na zona urbana e $2.675 \mathrm{~km}^{2}$ na zona rural (Perfil PMA 1999). Possui altitude média de $950 \mathrm{~m}$, altitude máxima de $1.087 \mathrm{~m}$ (Morro da Mesa), altitude mínima de $505 \mathrm{~m}$ (Rio Araguari), latitude de $18^{\circ} 11^{\prime} 30^{\prime \prime} \mathrm{S}$ e longitude de $48^{\circ} 11^{\prime} 18^{\prime \prime} \mathrm{W}$.

A temperatura média anual é de $21^{\circ} \mathrm{C}$, períodos mais quentes de outubro a março com médias de aproximadamente $27^{\circ} \mathrm{C}$, períodos mais frios entre junho ejulho com médias em torno de $16^{\circ} \mathrm{C}$. Oíndice pluviométrico anual é de $1.641 \mathrm{~mm}$.

\section{Abrigos estudados}

Foram estudados 54 abrigos agrupados em 12 tipos diferentes, conforme suas localizações e seeram artificiais ou naturais. Eles foram notificados, pelos proprietários rurais, ao Serviço VeterinárioOficial, de ataques aos animais de suas propriedades, por morcegos hematófagos.

Todos os abrigos pesquisados e visitados tiveram seus locais registrados com o auxílio de um Sensor Geográfico de Posição (GPS), modelo M 300, marca Magellan, com precisão de $100 \mathrm{~m}$. Esse sistema é amplamente utilizado nas mais diversas atividades humanas, para a localização de pontos, rotas e navegação (BRASIL, 2005).

\section{Estimativa populacional e dimensões dos abrigos}

A estimativa populacional das colônias de morcegos hematófagos, em cada abrigo, foi calculada por observação visual do número de indivíduos em cada nicho, correlacionado com o volume de fezes existentes no chão, paredes ou outras estruturas. Elas se caracterizam por serem negras em pequenas gotas (quando há poucos indivíduos no local) ou então manchas escorridas e poças de fezes (quando há muitos). Pode-se diferenciar seesseé um abrigo ativo, ou seja, se naquele momento há a presença de morcegos hematófagos; ou inativo, sejá houve essa presença. Nos abrigos ativos, as fezes são bem escuras, brilhantes e em estado pastoso, assemelhando-se a gotas de óleo queimado. Nos abrigos inativos, essas fezes estarão opacas e secas. O odor amoniacal de sangue digerido é característico nesses locais (BREDT, 1996; BREDT et al., 1998; BRASIL, 2005).

Para a definição dos agrupamentos de D. rotundus dentro dos abrigos, foi considerada que a maioria deles é constituída de 20 a 200 indivíduos. Apresenta estrutura social complexa, geralmentecom um macho dominante para defender cerca de 12 fêmeas e seus filhotes (BRASIL, 2005)

As dimensões dos abrigos foram estimadas para a área de piso $\mathrm{em}^{2}$, considerando-se um passo normal como equivalente a um metro linear. Os passos foram contados entre os dois pontos mais distantes na extensão horizontal e lateral do interior do abrigo (AlmEIDA et al., 2002).

\section{Identificação da espécie do Desmodus rotundus}

A identificação dos morcegos dessa espécie foi feita por equipes técnicas capacitadas e devidamente treinadas no controle de raiva dos herbívoros do Instituto Mineiro de Agropecuária (IMA).

Morfologicamente, caracteriza-se por ser um quiróptero de porte médio, possuindo uma envergadura de $37 \mathrm{~cm}$ e pesando por volta de $29 \mathrm{~g}$. As orelhas são curtas e apresentam extremidades pontiagudas, os olhos são grandes, o lábio inferior possui um sulco mediano em forma de $\mathrm{V}$. O polegar élongo, com três almofadas ou calosidades. A membrana interfemural 
époucodesenvolvida, com cerca de 19 mmna sua região mediana, tendo poucos pêlos curtoseespaçadosem sua superfície dorsal. O calcâneo é reduzido, assemelhando-se a uma pequena verruga (BRASIL, 2005). A pelagem ébastante macia, em geral de coloração cinza brilhante podendo apresentar tons avermelhados, dourados ou alaranjados (BERNARD, 2005).

\section{Métodos de controle do Desmodus rotundus}

Os abrigos identificados e cadastrados de morcegos hematófagos foram notificados ao Instituto Mineiro de Agropecuária (IMA), o qual celebra convênios com prefeituras municipais para a realização de capturas desses morcegos, devendo ser executadas por técnicos especializados e equipados.

Os métodos de controleutilizados foram o seletivo direto, onde há necessidade de captura do morcego hematófago e aplicação tópica do anticoagulante em seu dorso, e o seletivo indireto com aplicação tópica de dois gramas de pasta anticoagulante ao redor das mordeduras recentes de morcegoshematófagos ouno dorso do animal agredido, visando eliminar os morcegos agressores. Estes métodos deverão ser executados corretamente, de tal forma a atingir unicamente morcegos hematófagos da espécie $D$. rotundus, não causando dano ou transtorno a outras espécies. Esse controle está baseado na utilização de substâncias anticoagulantes (pastas vampiricidas), especificamente a warfarina (BRASIL, 2005).

\section{Análise dos dados}

Todas as informações foram anotadas em fichas e os abrigos caracterizados em relação às suas loca- lizações. Para a análise dos dados, foi utilizado o programa Epi info, versão 6.0 para o tratamento do banco de dados e os resultados foram descritos por meio de médias, medianas e proporções (DEAN et al., 1994).

\section{RESULTADOS}

Os 54 abrigos de morcegos hematófagos cadastrados no Município de Araguari, MG, em várias localidades de 51 propriedades rurais, foram agrupados em 12 tipos diferentes em ordem decrescente de suas freqüências: 18 casas abandonadas (33,4\%), 11 bueiros (20,5\%), 8 cavernas $(14,8 \%), 5$ pontilhões $(9,3 \%), 3$ pontes (5,6\%), 2 ocos de árvores (3,7\%), 2 usinas hidrelétricas $(3,7 \%), 1$ forno de carvoeira $(1,8 \%), 1$ cisterna $(1,8 \%), 1$ torre $(1,8 \%), 1$ paiol $(1,8 \%)$ e 1 viaduto (1,8\%), (Fig. 1).

Dentre os 54 abrigos de morcegos hematófagos notificados, $44(81,5 \%)$ eram abrigos artificiais e 10 (18,5\%) eram naturais.

Nesses abrigos foram encontrados morcegos de diversas espécies, entretanto, somente a espécie hematófaga $D$. rotundus foi identificada.

Ao estimar-se a população das colônias de morcegos hematófagos, nos 54 abrigos cadastrados no momento da sua descoberta a partir do ano de 1996, foram encontrados $3(5,5 \%)$ desabrigados (população zero), $42(77,8 \%)$ com população estimada entre 1 a 50 morcegos hematófagos, 9 (16,7\%) abrigos com população entre 51 a 300 e nenhum com população acima de 300 indivíduos. A população mediana das colônias foi estimada em 30,2 indivíduos por abrigo.

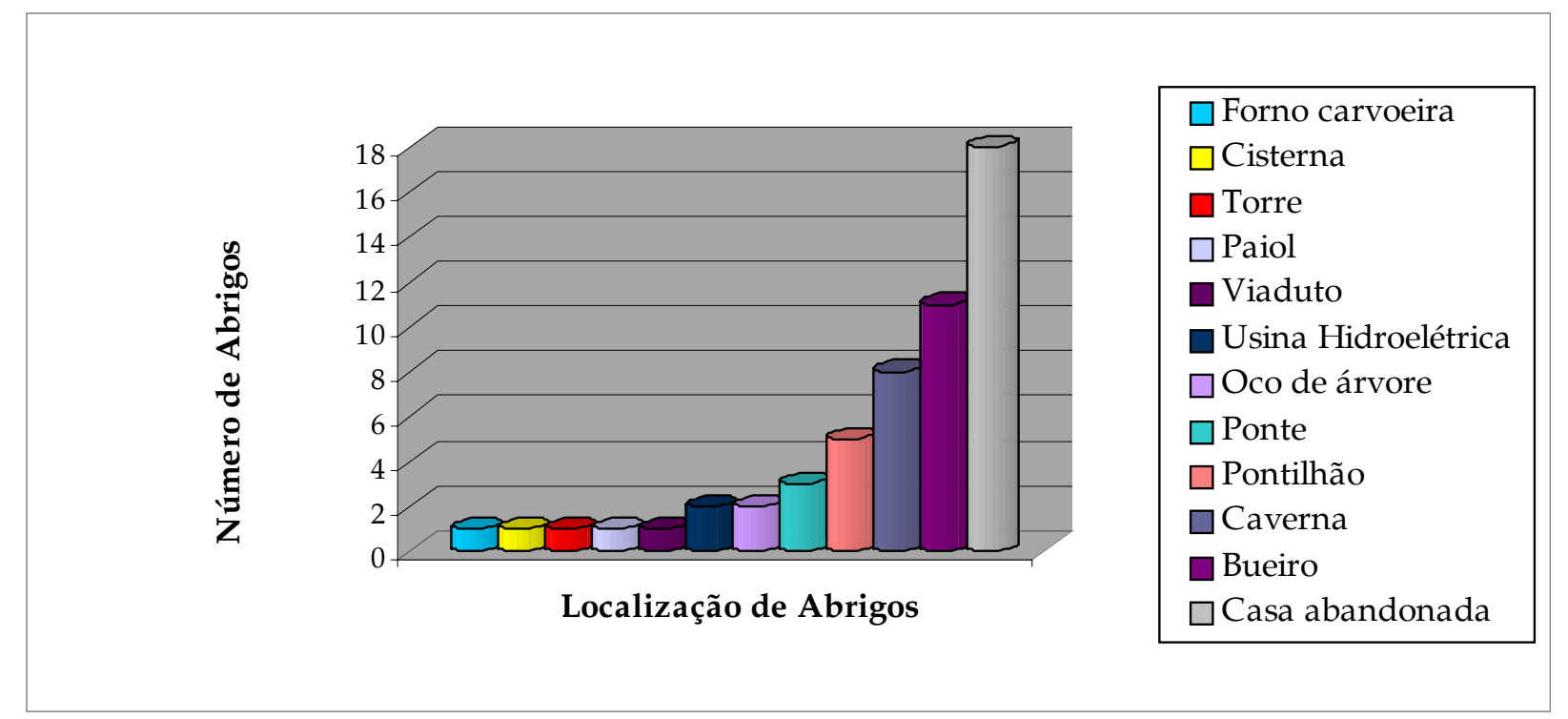

Fig. 1 - Localização em ordem crescente dos 54 abrigos de morcegos hematófagos, encontrados no Município de Araguari, MG, no período de 1996 a 2003. 


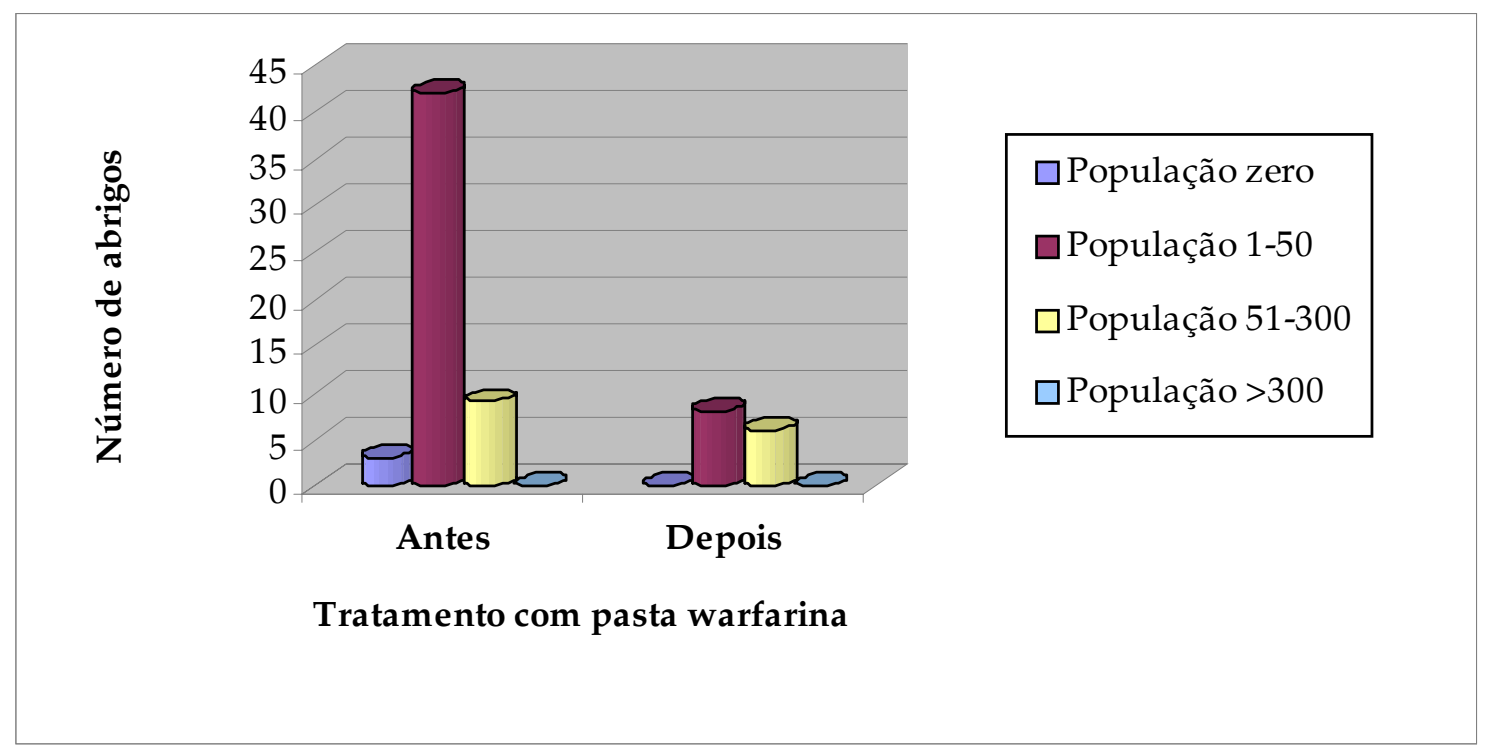

Fig. 2 - Comparação dos dados sobre as estimativas das populações nos abrigos antes e após tratamento, com a pasta warfarina, no Município de Araguari, MG, no período entre 1996 a 2003.

Para o controle da população das colônias do $D$. rotundus, foi realizado tratamento com o anticoagulante warfarina, nos abrigos encontrados em atividade e nos animais domésticos agredidos, durante o período de 1996 a 2003. Tanto o método de controle seletivo direto quanto o indireto foram utilizados pelo serviço de Defesa Sanitária Animal, do Município de Araguari.

Antes do tratamento existiam 42 abrigos com população estimada entre 1 a 50 morcegos hematófagos. Nas visitas após esse tratamento foi observado que em $34(81,0 \%)$ deles as populações das colônias foram eliminadas, restando $8(19,0 \%)$ abrigos habitados. Enquanto que nos nove abrigos com população estimada entre 51 a 300 hematófagos, apenas $3(33,3 \%)$ foram desabitados, restando ainda 6 (66,7\%) abrigos em atividade. Portanto, após o tratamento, do total de 51 abrigos habitados, 37 (72,5\%) foram desabitados pelo $D$. rotundus e $14(27,5 \%)$ abrigos continuavam em atividade.

A comparação dos dados sobre as estimativas das populações nos abrigos antes e após tratamento com a pasta warfarina estão representados na (Fig 2).

A mediana de hematófagos estimada foi de 47,9 indivíduos por abrigo, após tratamento com esse anticoagulante.

\section{DISCUSSÃO}

Os 54 abrigos cadastrados de morcegos hematófagos, da espécie $D$. rotundus, estavam distribuídos de forma difusa em 51 propriedades do $\mathrm{Mu}$ nicípio de Araguari, MG. De acordo com relatos na literatura, dentre as espécies de hematófagos é a mais comumente encontrada no Brasil e em Minas Gerais (Silva, 1999; Stutz, 2004). Capturas realizadas no complexo da Lapinha, no Município de Lagoa Santa, MG, mostraram que dentre as 42 espécies de morcegos encontradas, $44,4 \%$ eram $D$. rotundus (FANTAUZZI, 1997). No Estado do Ceará, essa mesma espécie de morcego hematófago tambémé predominante (MorAIs, 2001).

A maioria dos 54 abrigos de D. rotundus, cadastrados neste estudo, situava-se próximas a leito de rios, dentre os quais $44(81,5 \%)$ eram abrigos artificiais, tais como casas abandonadas, bueiros, pontilhões e pontes. Os outros $10(18,5 \%)$ abrigos eram naturais (cavernas, ocos de árvores etc.). De um modo geral, encontrou-se maior ocorrência em casas abandonadas, bueiros e cavernas, respectivamente. As menores frequências desses abrigos foram encontradas em fornos de carvoeiras, cisternas, torres, paiol e viaduto.

Estes dados estão em concordância com aqueles encontrados no Estado de São Paulo, a respeito das colônias de $D$. rotundus. Do total de abrigos, $66,7 \%$ eram artificiais (pontes, casas e bueiros) e 33,3\% naturais (grutas), em propriedades rurais às margens de rios (UIEDA, 1995; GOMES et al., 2000).

Em outros estudos também realizados no Estado deSãoPaulo, em 113 refúgios diurnos, localizadosem 122 municípios, revelaram que apenas $28(24,8 \%)$ dos abrigos de $D$. rotundus eram naturais. Os outros 85 $(46,9 \%)$ eram artificiais, compostos por casas abandonadas no campo, fornos de carvão em desuso, bueiros sob rodovias e outras estruturas similares. A maioria desses abrigos localizava-se, também, próxima aos principais rios paulistas (TADDEI et al., 1991). 
Outra consideração referente a estudos com $D$. rotundus mostrou que essa espécie habita grande variedade de abrigos, sendo os mais comuns: grutas de pedras, túneis, poços d'água e bueiros. Em telhados de residências e ocos de árvores também foram encontrados abrigos, locais considerados de baixa presença de morcegos hematófagos (HILL; SMITH, 1984).

Vários outros trabalhos já relataram a capacidade dessa espécie em utilizar diferentes tipos de abrigos (DitMARS; GREENHALL, 1935; TADDEI et al., 1991; BREDT et al., 1998), principalmente por se adaptarem às modificações introduzidas pelo homem ao ambiente (GREENHALL, 1993). Essa capacidade, sob diferentes condições, mostra a grande versatilidade adaptativa de D. rotundus (SAZIMA, 1978; TADDEI et al., 1991; BREDT et al., 1998).

Na região cárstica de Cordisburgo eno Município de Curvelo, MG, em 49 abrigos vistoriados (29 naturais e 20 artificiais), localizados em 14 propriedades, encontrou-se o $D$. rotundus exclusivamente em 18 $(36,7 \%)$ abrigos naturais. Destes, 17 eram cavernas formadas pela dissolução ou abatimento de rocha calcária, e um era túnel escavado na terra pela ação das águas de um rio (Almeida et al., 2002).

No presente estudo, com relação ao número de indivíduos das colônias, 82,3\% dos 51 abrigos habitados, durante o período da pesquisa, possuíam população estimada entre 1 a 50 hematófagos e 17,6\% entre 51 a 300 indivíduos.

A maioria dos agrupamentos de $D$. rotundus é constituída por 20 a 100 indivíduos (BRASIL, 2005). Alguns autores consideram que colônias com mais de 51 indivíduos são antigas e estabilizadas. Estudos realizados noEstado deSãoPaulo demonstraram que 58\% das colônias continham mais de 151 indivíduos (TADDEI et al., 1991). Outros estudos consideram que colônias com população acima de 100 indivíduos ocorrem em regiões onde o trabalho de controle de populacional não é feito com regularidade (UIEDA et al., 1996).

A população mediana estimada de morcegos da espécie D. rotundus, neste estudo, foi de 47,9 por abrigo. Esse tamanho é considerado dentro do habitual que é de 20 a 100 indivíduos (GREENHALl et al., 1983; GreENHALL, 1993; UiedA et al., 1996).

A eliminação das populações das colônias, do $D$. rotundus, em 37 abrigos após o tratamento com a pasta vampiricida warfarina, significou uma redução de $72,5 \%$ do total dos abrigos habitados, durante o período deste estudo. Esses resultados mostraram a eficiência da aplicação desse método de controle populacional, para os morcegos hematófagos.

A maioria das populações das colônias que foram eliminadas tinha entre 1 a 50 morcegos hematófagos. Dentre os 14 abrigos que permaneceram habitados, grande parte deles possuía população estimada entre 51 a 300 indivíduos, provavelmente devido ao fato das colônias serem mais antigas e mais estabilizadas ou ainda pelo formato e estrutura dos abrigos.

No Brasil, poucos trabalhos foram descritos sobre os abrigos utilizados por diversas espécies de morcegos, inclusive de D. rotundus, e a sua distribuição no interior deles. Suspeita-se que a composição das colônias dessa espécie e sua distribuição no interior dos abrigos diurnos devem interferir na eficiência do controle de suas populações, por meio da pasta vampiricida de aplicação tópica nos morcegos. Uma colônia dividida em vários subgrupos, vivendo espalhados no interior do abrigo, deve ser mais difícil de eliminar do que uma colônia compacta vivendo em apenas um local do abrigo. Nessa situação, o formato e a estrutura dos abrigos devem influir no formato das colônias (BREDT et al., 1999).

\section{CONCLUSÕES}

O Município de Araguari, MG, apresenta condições propícias para a permanência e sobrevivência dessa espécie de morcego. Dada as características da interação do $D$. rotundus com o meio ambiente, o ecossistema tem a capacidade de albergar populações dessa espécie, devido à disponibilidade de alimento e de abrigos.

Os abrigos artificiais representam o principal tipo de abrigo encontrado no município em detrimento dos abrigos naturais e a proximidade de rios é um fator importante para o estabelecimento de abrigos ativos.

A versatilidade de adaptação do $D$. rotundus, aliada a quase ausência de predadores naturais, adicionados à falta de controle populacional pelos órgãos oficiais, a disponibilidade de alimentos e abrigos, têm proporcionado ao $D$. rotundus condições de crescimento de suas populações. Este crescimento só poderá ser reduzido por meio de uma forte pressão de controle de efeito prolongado, com monitoramento pelo menos uma vez por ano, associado a um programa permanente de educação.

A análise desses dados permitiu concluir que é imperativo desenvolver programas de rotina, visando manter as populações do $D$. rotundus em níveis toleráveis, para controlar a raiva dos herbívoros.

\section{REFERÊNCIAS}

ACHA, P.N.; MÁLAGA-ALBA, M. Economic losses due to Desmodus rotundus. In: GREENHALL, A.M.; SCHMIDT, U. (Ed.). Natural history of vampire bats. Flórida: CRC Press, 1988. p.207-214. 
ALENCAR, A.O. Aspectos biológicos e ecológicos do Desmodus rotundus rotundus, Chiroptera (E. Geoffroy, 1810) no Nordeste do Brasil. 1997. 88f. Dissertação (Mestrado em Ciências Veterinárias) - Escola de Veterinária da Universidade Federal de Minas Gerais, Belo Horizonte, 1997.

ALMEIDA, E.O.; MOREIRA, E.C.; NAVEDA, L.A.B.; HERRMANN, G.P. Combate ao Desmodus rotundus rotundus (E. Geoffroy,1810) na região cárstica de Cordisburgo e Curvelo, Minas Gerais. Arquivo Brasileiro Medicina Veterinária e Zootecnia, n.54, p.117-126, 2002.

BIANCONI, G.V.; MIKICH, S.B.; PEDRO, W.A. Diversidade de morcegos (Mammalia, Chiroptera) em remanescentes florestais do Município de Fênix, noroeste do Paraná, Brasil. Revista Brasileira de Zoologia, n.21, p.943-954, 2004.

BRASIL. Ministério da Agricultura, Pecuária e Abastecimento. Controle da raiva dos herbívoros. Brasília: MAPA/SDA/DAS, 2005.104p.

BRASIL. Ministério da Saúde. Programa Nacional de Profilaxia da Raiva. Casos de raiva humana notificados e percentual de casos transmitidos segundo a espécie animal. Brasília, 2005.

BERNARD, E. Morcegos vampiros: sangue, raiva e preconceito. Ciência Hoje, n.214, p.44-49, 2005.

BREDT, A. Morcegos em áreas urbanas e rurais: manual de manejo e controle. Brasília: Ministério da Saúde. Fundação Nacional da Saúde, 1996. 117p.

BREDT, A.; ARAÚJO, F.A.A.;CAETANO-JUNIOR,J.; RODRIGUES, M.G.R.; YOSHIKAWA, M.; SILVA, M.M.S. Morcegos em áreas urbanas e rurais: manual de manejo e controle. Brasilia: Fundação Nacional da Saúde, Brasília, 1998. 117p.

BREDT, A.; UIEDA, W.; MAGALHÃES, E.D. Morcegos cavernícolas da região do Distrito Federal, Centro Oeste do Brasil (Mammalia, Chiroptera). Revista Brasileira de Zoologia , n.16, p.731-770, 1999.

CUNHA-VIEIRA, C.O. Ensaio monográfico sobre os quirópteros do Brasil. Arquivos de Zoologia, n.3, p.219$247,1942$.

DEAN, A.G.; DEAN, J.A.; COULOMBIER, D.; BRENDEL, K.A.; SMITH, D.C.; BURTON, A.H. Epi info, version 6: a word processing database and statistics program for epidemiology on microcomputers. Atlanta: Centers of Disease Control and Prevention, 1994. 589p.

DITMARS, R.L.; GREENHALL, A.M. The vampire bats: presentation of underscribed habits and review of its history. Zoologica, n.19, p.53-76, 1935.

FANTAUZZI, L. Levantamento de espécies de morcegos e controle populacional das espécies hematófagas no complexo da Lapinha-Lagoa Santa-MG. In: JORNADA DE BIOLOGIA, 13., 1997, São Paulo, SP. Resumos. São Paulo, 1997.

FLORES-CRESPO, R.; LINHART, S.B.; BURNS, R.J.; MITCHELL, G.C. Foraging behavior of the common vampire bats related to moonlight. Journal Mammalogy, n.53, p.366-368, 1972.

GOMES, M.N.; CHAIM, J.M.; PENTEADO, F.A.M. Característica por geoprocessamento da epidemia migratória de raiva em herbívoros na região de Mogi das Cruzes, SP. Arquivos do Instituto Biológico, São Paulo, v.67, p.38, 2000. Suplemento. Trabalho apresentado na REUNIÃO ANUAL DO INSTITUTO BIOLÓGICO, 13., 2000, São Paulo, São Paulo, Resumo 024 .

GONÇALVES, M. Estudo da relação causal do surto de raiva em 1991/1992, provocados por morcegos em três municípios (Conde, Aporá e Ipirá) do Estado da Bahia. 1996 Monografia - Departamento de Zoologia, Universidade Federal da Bahia, Ondina, 1996.

GRENNHALL, A.M.; JOERMANN, G.; SCHIMDT, U. Desmodus rotundus. Mammalian Species, n.202, p.1-6, 1983.

GREENHALL, A.M.; Ecology and bionomics of vampire bats in Latin America. In: GREENHALL, A.M.; ARTOIS, M.; FEKADU, M. (Ed.). Bats and rabie. Lyon: Marcel Mérieux, 1993. 107p.

HILL, J.E.; SMHIMDT, J.D. Bats: a natural history. London: British Museum of Natural History, 1984. 243p.

HUNT, L.A.; BHATNAGAR, K.P. Human rabies and Silver-haired bats in the United States. Bat Research News, n. 38, p.85-89, 1997.

HUSSON, A.M. The bats of Suriname. Zoologische Verhandelingen, n.58, p.1-282, 1962.

KOOPMANN, K.F. Systematics and distribution. In: GREENHALL, A.M.; SCHIMDT, U. (Ed). Natural history of vampire bats. Flórida: CRC Press, 1988. p.7-17.

KOTAIT, I.; TAKAOKA, N.Y.; PANACHÃO, M.R.I.; SODRÉ, M.M.; FIGUEIREDO, A.C.C.; SCHIMONSKY, B.V. et al. Manejo de quirópteros em áreas urbanas. São Paulo: Manual Técnico do Instituto Pasteur, 1998. 45p. (Manual Técnino n.7).

MORAIS, N. Animais também mordem o homem que corre perigo de contrair a raiva. Diário do Nordeste-Regional, Fortaleza, 17 mar. 2001.

PICCININI, R.S. Controle de morcegos hematófagos: análise e discussão dos métodos existentes. Boletim Defesa Sanitária Animal, n.16, p.116-157, 1982. 
ROCHA, J.H.; ABDALA, V.L.; RIBEIRO, A.G. A distribuição espacial da raiva desmodina no Município de Araguari-MG no período de 2000 a 2002. In: SIMPÓSIO REGIONAL DE GEOGRAFIA, 2., 2003, Uberlândia, MG. Resumo. Uberlândia: Instituto de Geografia-Universidade Federal de Uberlândia, 2003.

SAZIMA, I. Aspectos do comportamento alimentar do morcego hematófago Desmodus rotundus. Boletim de Zoologia, n.3, p.97-119, 1978.

SILVA, J.A. Organização do espaço agrário e a distribuição da raiva bovina em Minas Gerais, 1976 a 1997. 1999. 172f. Tese (Doutorado) - Universidade Federal de Minas Gerais, Belo Horizonte, 1999.

STUTZ, W.H.; ALBUQUERQUE, M.C.; UIEDA, W.; MACEDO, E.M.; FRANÇA, C.B. Updated list of bats from Uberlândia, state of Minas Gerais, southeastern Brazil. Chiroptera Neotropical, n.10, p.1-2, 2004.

TADDEI, V.A.; GONÇALVES, C.A.; PEDRO, W.A.; TADDEI, W.J.; KOTAIT, I.; ARIETA, C. Distribuição do morcego vampiro Desmodus rotundus (Chiroptera, Phyllostomidae) no Estado de São Paulo e a raiva dos animais domésticos. Campinas: Secretaria de Agricultura e Abastecimento do Estado de São Paulo, 1991. 107p.

UIEDA, W. The common vampire bat in urban environments from Southeastern Brasil. Chiroptera Neotropical, n.1, p.22-24, 1995.

UIEDA, W.; HAYASHI, M.M.; GOMES, L.H.; SILVA, M.M. Espécies de quirópteros diagnosticadas com raiva no Brasil. São Paulo: Boletim do Instituto Pasteur, 1996. n.2, p.17-36.

YALDEN, B.W.; MORRIS, P.A. The lives of bats. Newton Abbot: David \& Charles, 1975. 247p.

Recebido em 18/8/08

Aceito em 11/8/09 